\title{
MicroRNA-431 inhibits the expression of surfactant proteins through the BMP4/activin/TGF- $\beta$ signaling pathway by targeting SMAD4
}

\author{
YAN-QING SHEN $^{1 *}$, ZHI-DAN BAO $^{1 *}$, JING-JING PAN $^{2}$, XIAO-NAN MAO $^{1}$, RUI CHENG $^{1}$, \\ XIAO-GUANG ZHOU ${ }^{1}$, XIAO-YU ZHOU ${ }^{1}$ and YANG YANG ${ }^{1}$ \\ ${ }^{1}$ Department of Neonates, Children's Hospital of Nanjing Medical University, Nanjing, Jiangsu 210008; \\ ${ }^{2}$ Department of Pediatrics, First Affiliated Hospital of Nanjing Medical University, Nanjing, Jiangsu 210029, P.R. China
}

Received July 15, 2019; Accepted January 13, 2020

DOI: $10.3892 /$ ijmm.2020.4511

\begin{abstract}
The synthesis and secretion of surfactant proteins (SPs) is an important sign of lung maturation. Furthermore, the morbidity of lung developmental diseases, including respiratory distress syndrome and bronchopulmonary dysplasia which are mainly caused by immature lung development and lack of SPs, is increasing. As is well known, multiple microRNAs (miRs/miRNAs) are able to influence lung development via numerous different signaling pathways. However, few studies examine the association between the miRNAs and lung developmental diseases. A previous study has demonstrated that miR-431 was significantly $(\mathrm{F}=33.49 ; \mathrm{P}<0.001)$ downregulated in the lung tissues of Sprague-Dawley rats at 3 time points, embryonic day 19, embryonic day 21 and postnatal day 3 . The present study reported that the regulation of miR-431 may influence the expression of SPs. Thus, the further potential mechanisms of miR-431 in negatively regulating lung development were examined in the present study. Stable A549 cell lines overexpressing or knocking down SMAD family member 4 (SMAD4) transfected with miR-431 overexpressed or knocked down, and their control groups were established. Subsequently, the expression of bone morphogenetic protein 4 (BMP4), SMAD4 and SPs (SP-A, SP-B and SP-C) at the RNA and protein levels were validated respectively by reverse transcription quantitative PCR and western blotting. miR-431 exhibited a decreased expression, while BMP4 and SPs exhib-
\end{abstract}

Correspondence to: Dr Yang Yang or Dr Xiao-Yu Zhou, Department of Neonates, Children's Hospital of Nanjing Medical University, 72 Guangzhou Road, Nanjing, Jiangsu 210008, P.R. China

E-mail: 15952071803@163.com

E-mail: xyzhou161@163.com

*Contributed equally

Key words: microRNA-431, SMAD family member 4, bone morphogenetic protein 4/activin/transforming growth factor- $\beta$ signaling pathway, surfactant proteins ited increased expression at the mRNA and protein levels in the SMAD4 knockdown group. Meanwhile, the expression of SPs were reduced in the SMAD4-knockdown group via overexpressing miR-431 and increased in the SMAD4-overexpression group via inhibiting miR-431. The present results indicate that SMAD4 negatively regulates the expression of SPs, and that miR-431 negatively regulates the expression of SPs through inhibiting the BMP4/activin/transforming growth factor- $\beta$ signaling pathway by targeting SMAD4.

\section{Introduction}

In the last 25 years, the rate of preterm births has increased by approximately one-third globally (1). The majority of preterm infants are born during the saccular stage of lung development (26 to 36 gestational weeks), while the lung structure is immature, with deficient surfactant proteins (SPs), delayed absorption of intrapulmonary fluid and inefficient gas exchange (2). Accumulating evidence in previous years has demonstrated a consistently high risk of respiratory morbidity in infants born at $<37$ weeks of gestation (3). Lung development is a complex process with a series of orchestrated events. Premature birth interrupts normal lung development, which results in a series of respiratory diseases (4). Neonatal respiratory distress syndrome (RDS), a condition of pulmonary insufficiency that in its natural course commences at or shortly following birth and increases in severity over the first $48 \mathrm{~h}$ of life, is a common disease in preterm babies (5). RDS occurs in $\sim 45 \%$ of early or moderate-preterm infants (23-33 weeks of pregnancy) (5). The main cause of RDS is a deficiency of SPs along with structural immaturity $(4,5)$. Thus, improving the understanding of lung development may hold promise for improving the prevention and treatment of respiratory diseases in preterm infants.

MicroRNAs (miRNAs/miRs) are a class of small non-coding RNAs that are 22 nucleotides long, and that inhibit the translation of target mRNAs, serving an important function in cell proliferation, differentiation and organ development (6). A number of studies have documented that $>100$ miRNAs undergo substantial changes in expression during lung development $(6,7)$. However, little is known about 
if or how they regulate lung development. A previous study reported that miR-431 expression is higher in preterm infants with RDS compared with those without RDS (8). Additionally, miR-431 was revealed to be downregulated in the lung tissues of Sprague-Dawley rats at 3 time points, embryonic day 19 , embryonic day 21 and postnatal day 3 , by reverse transcription quantitative PCR (RT-qPCR) and fluorescence in situ hybridization (9).

Alveolar epithelial type II (AECII) cells are specialized epithelial cells for maintaining lung function and homeostasis, and are able to regulate the metabolism of alveolar surfactants, express innate immune molecules, and regenerate and restore alveoli in response to an injury $(10,11)$. Tumor AECII cell lines fail to fully recapitulate alveolar epithelial cell phenotypes in vivo. However, the A549 cell line is a classic human type II alveolar epithelial cell line, which contains lamellar bodies producing surfactant and containing a phospholipid content similar to that of AECII cells in situ (12). Therefore, A549 cells have the majority of the functions of type II cells. In a previous study, SMAD family member 4 (SMAD4) was identified as an important target of miR-431 in A549 cells; the overexpression of miR-431 was able to accelerate the proliferation of A549 cells, inhibit apoptosis and downregulate the expression of SPs $(13,14)$. Thus, it was hypothesized that miR-431 is critical for the expression of SPs and it serves a regulatory function similar to the bone morphogenetic protein 4 (BMP4)/activin/transforming growth factor $\beta$ (TGF- $\beta$ ) signaling pathway.

As a member of the SMAD family, SMAD4 is a common mediator of the TGF- $\beta$ signaling pathway. One previous study reported that, in the canonical signaling pathway, activated SMAD2 and SMAD3 form a complex with SMAD4, a component shared by all TGF- $\beta$ family members, and this complex translocates to the nucleus to regulate the transcription of target genes (15). Notably, increasing evidence suggests that SMAD4-dependent TGF- $\beta$ signaling serves an important function in the differentiation of endodermal cells and inhibits the epithelial to mesenchymal transition process, which is essential for lung branching morphogenesis $(16,17)$. BMP4 belongs to the TGF- $\beta$ superfamily and is a multifunctional peptide with important functions in normal lung development (18).

In the present study, the functions of miR-431 and its target gene SMAD4 were investigated to follow on from previous studies. The present study aimed to determine the potential mechanisms of miR-431 in the regulation of lung development. The results of the present study may provide crucial molecular and cellular evidence of the potential of miR-431 as a marker of fetal lung development and as a therapeutic target for lung developmental diseases.

\section{Materials and methods}

Cell culture. The human non-squamous cell lung carcinoma line (A549 cell line), obtained from the American Type Culture Collection (Manassas, VA, USA), were seeded and grown in Dulbecco's modified Eagle's medium (DMEM; Gibco; Thermo Fisher Scientific, Inc., Waltham, MA, USA) supplemented with $10 \%$ fetal bovine serum (FBS; Gibco; Thermo Fisher Scientific, Inc.) and (100 U/ml) 1\% penicillin and $100 \mu \mathrm{g} / \mathrm{ml}$ streptomycin; Gibco; Thermo Fisher Scientific, Inc.) at the condition of $37^{\circ} \mathrm{C}$ in a humidified incubator containing $5 \% \mathrm{CO}_{2}$.

Generating stable cell lines with lentivirus. The lentivirus of the overexpression of SMAD4 (LV-SMAD4 ${ }^{+}$), the lentivirus of the knockdown of SMAD4 (LV-SMAD4 ${ }^{-}$) and their corresponding controls (LV-SMAD4+-NC and LV-SMAD4-NC) were obtained from Shanghai GenePharma Co., Ltd. (Shanghai, China). LV-SMAD4 ${ }^{+}$and LV-SMAD4 ${ }^{+}-\mathrm{NC}$ were used with adenovirus-based vectors containing the green fluorescent protein (GFP) gene and puromycin-resistant marker (cat. no. AAV5-EF-1a-GFP\&Puro; Shanghai GenePharma Co., Ltd.), while LV-SMAD4- and LV-SMAD4-NC were used with different adenovirus-based vectors containing the GFP gene and puromycin-resistant marker (cat. no. AAV3-H1-GFP\&Puro; Shanghai GenePharma Co., Ltd.). In detail, LV-SMAD4 ${ }^{+}$synthesized and cloned the SMAD4 gene (gene ID: NM_005359.5) into the vector AAV5-EF-1a-GFP\&Puro, and LV-SMAD4+-NC used the empty vector AAV5-EF-1a-GFP\&Puro. Meanwhile, LV-SMAD4- synthesized and cloned the SMAD4-homo-1506 (5'-GGTGTTCCATTGCTTACTTTG-3') into the vector AAV3-H1-GFP\&Puro, and LV-SMAD4-NC synthesized and cloned a universal sequence (5'-TTCTCCGAACGTGTC ACGT-3') into the vector AAV3-H1-GFP\&Puro. In additional, the LV-SMAD4- knockdown of endogenous SMAD4 was performed. To minimize the off-target effects of RNA interference, three potential sequences targeting the human SMAD4 gene were constructed and the shRNA sequence (5'-GGTGTTCCATTGCTTACTTTG-3') was selected for the subsequent experiment. The selected SMAD4 shRNA sequence and a scrambled sequence (5'-TTCTCCGAACGT GTCACGT-3') with no homology to any known human genes were synthesized and ligated into the AAV3-H1-GFP\&Puro adenovirus-based vector. A549 cell lines were cultured in the 96-well plate at a concentration of $5 \times 10^{4}$ cells/well, mixed and incubated at the condition of $37^{\circ} \mathrm{C}$ in a humidified incubator containing $5 \% \mathrm{CO}_{2}$ for $24 \mathrm{~h}$. Then, $10 \mu \mathrm{l}$ lentiviral stock was diluted 1:10 in DMEM medium containing 10\% FBS, and polybrene was added at a concentration of $5 \mu \mathrm{g} / \mathrm{ml}$. Next, the culture medium was aspirated in a 96-well plate, and $100 \mu \mathrm{l}$ of each of the aforementioned diluted virus solution was added to each well, a blank control group was set up, and incubated with Polybrene (Shanghai GenePharma Co., Ltd.) to a final concentration $6 \mu \mathrm{g} / \mathrm{ml}$ for $24 \mathrm{~h}$ at $37^{\circ} \mathrm{C}$ in a humidified incubator containing $5 \% \mathrm{CO}_{2}$. Finally, the diluted virus solution was aspirated from the 96-well plate and $100 \mu \mathrm{l}$ DMEM containing $10 \%$ FBS was added to each well and cultured for 72 or $96 \mathrm{~h}$, and the lentivirus infection efficiency was observed under an optical microscope (x100 magnification; DM2500; Leica Microsystems GmbH, Wetzlar, Germany) and a fluorescent microscope (BX51; Olympus Corporation, Tokyo, Japan). Meanwhile, a concentration gradient of puromycin was established $(0,0.1,0.2,0.4$, $0.6,0.8,1.0,1.2,1.5,2.0,2.5$ and $3.0 \mu \mathrm{g} / \mathrm{ml}$; Sigma-Aldrich; Merck KGaA, Darmstadt, Germany) to screen for the optimal puromycin concentration that completely killed the cells. Finally, the stable cell lines were verified by RT-qPCR and western blotting. 
Table I. Primers for reverse transcription-quantitative PCR.

\begin{tabular}{ll}
\hline Gene name & \multicolumn{1}{c}{ Primers } \\
\hline miR-431 reverse transcription primer & 5'-GTCGTATCCAGTGCAGGGTCCGAGGTATTC \\
miR-431 & GCACTGGATACGACTGCATG-3' \\
& F: 5'-ACGCGTGTCTTGCAGGCCGT-3' \\
SP-A & R: 5'-ATCCAGTGCAGGGTCCGAGG-3' \\
& F: 5'-TGTGTGCGAAGTGAAGGACG-3' \\
SP-B & R: 5'-CTTTGAGACCATCTCTCCCGT-3' \\
& F: 5'-AGGACACGATGAGGAAGT-3' \\
SP-C & R: 5'-AGTCTGGTTCTGGAAGTAGT-3' \\
& F: 5'-CACCTGAAACGCCTTCTTATCG-3' \\
SMAD4 & R: 5'-TTTCTGGCTCATGTGGAGACC-3' \\
BMP4 & F: 5'-CTCATGTGATCTATGCCCGTC-3' \\
& R: 5'-AGGTGATACAACTCGTTCGTAGT-3' \\
U6 & F: 5'-GACCACCTCAACTCAACCAACCA-3' \\
& R: 5'-GCACCCACATCCCTCTACTACCAT-3' \\
GAPDH & F: 5'-CTCGCTTCGGCAGCACA-3' \\
& R: 5'-AACGCTTCACGAATTTGCGT-3' \\
& F: 5'-AGAAGGCTGGGGCTCATTTG-3' \\
60
\end{tabular}

SMAD4, SMAD family member 4; BMP4, bone morphogenetic protein 4; SP, surfactant proteins; miR, microRNA; F, forward; R, reverse.

miR-431 mimic, miR-431 inhibitor and cell transfection. miR-431 mimic, miR-431 inhibitor and the corresponding control (mimic-NC and inhibitor-NC) were synthesized by Guangzhou RiboBio Co., Ltd. Stable cell lines (LV-SMAD4 ${ }^{+}$ and LV-SMAD4 ${ }^{-}$) were transfected with miR-431 mimics, an miR-431 inhibitor and the corresponding negative control with Lipofectamine 3000 (Invitrogen; Thermo Fisher Scientific), according to the manufacturer's protocol. Mixture A contained $125 \mu \mathrm{l}$ DMEM and $5 \mu \mathrm{l}$ Lipofectamine 3000. Mixture B contained $125 \mu \mathrm{l}$ DMEM and $10 \mu 1$ mimic or inhibitor or the corresponding control. The two mixtures were left to stand at room temperature for $10 \mathrm{~min}$ initially, and then mixed and left for a further $10 \mathrm{~min}$. The complex was then added to each well of the 6 -well plate and incubated for $24 \mathrm{~h}$ at $37^{\circ} \mathrm{C}$. Finally, the Lipofectamine 3000 mixture was aspirated, and DMEM supplemented with $10 \%$ FBS was added and cultured for $48 \mathrm{~h}$. In brief, cells (LV-SMAD4 ${ }^{+}$and LV-SMAD4 ${ }^{-}$) were plated in 6 -well plates. When cells reached a confluence of $\sim 50 \%$ in complete growth medium, cells were transfected with $50 \mathrm{nM}$ mimics or $100 \mathrm{nM}$ inhibitors and incubated for 48 or $72 \mathrm{~h}$ for RNA or protein extraction. The miR-431 sequence used was accession no. MIMAT0001625, 5'-UGUCUUGCAGGCCGU CAUGCA-3'.

RNA extraction, cDNA synthesis and RT-qPCR. Total RNA was isolated from cells (A549 cells treated as above) by TRIzol reagent (Invitrogen; Thermo Fisher Scientific, Inc.). The RNA concentration were detected using a NanoDrop2000 Spectrophotometer (Thermo Fisher Scientific, Inc.). The conversion of miR-431 into cDNA was performed with the HiScript ${ }^{\circledR}$ II Q Select RT SuperMix for qPCR (cat. no. R232-01;
Vazyme, Piscataway, NJ, USA) according to the manufacturer's protocol [including $4 \mu 1$ 5x HiScript II Select qRT SuperMix, $1 \mu \mathrm{lmiR}-431$-primer (50 ng/ $\mu \mathrm{l})$ and $1 \mu \mathrm{g} \mathrm{RNA}]$. The RT primer of miR-431 was designed and synthesized by Generay Biotech Co., Ltd. and is listed in Table I. Reverse transcription of $1 \mu \mathrm{g}$ RNA isolated from A549 cells into cDNA was performed using the HiScript ${ }^{\circledR}$ II Q Select RT SuperMix for qPCR (cat. no. R222-01; Vazyme) according to the manufacturer's protocol [including $4 \mu 1$ 5x HiScript II Select qRT SuperMix and $1 \mu \mathrm{g}$ RNA]. The RT reaction was conducted at $37^{\circ} \mathrm{C}$ for $15 \mathrm{~min}$ and $85^{\circ} \mathrm{C}$ for $2 \mathrm{~min}$. Next, the RT-qPCR reaction was performed with $\mathrm{AceQ}^{\circledR} \mathrm{qPCR}$ (cat. no. Q131-01; Vazyme) according to the manufacturer's protocol (including $1 \mu \mathrm{l}$ cDNA, $5 \mu 1 \mathrm{SYBR}^{\circledR}$ Green Master Mix, $0.2 \mu \mathrm{l}$ reverse and forward primers and $3.6 \mu 1$ diethypyrocarbonate water) on an ABI 7500 thermal cycler (Applied Biosystems; Thermo Fisher Scientific, Inc.). The thermocycling conditions included an initial step at $95^{\circ} \mathrm{C}$ for $5 \mathrm{~min}, 40$ cycles at $90^{\circ} \mathrm{C}$ for $15 \mathrm{sec}$ and at $60^{\circ} \mathrm{C}$ for $15 \mathrm{sec}$, $72^{\circ} \mathrm{C}$ for $1 \mathrm{~min}$ and final extension at $72^{\circ} \mathrm{C}$ for $10 \mathrm{~min}$. U6 was used as the internal control of miR-431. GAPDH was used as the internal control of all other genes (SMAD4, BMP4 and SPs). All primer sequences used were designed and synthesized by Generay Biotech Co., Ltd. and are listed in Table I. The relative mRNA expression was measured using the $2^{-\Delta \Delta \mathrm{Cq}}$ method (19).

Western blotting. Cells (A549 cells treated as above) were harvested and lysed in RIPA buffer (Beyotime Institute of Biotechnology) containing a protease inhibitor and phosphatase inhibitor cocktail (Beyotime Institute of Biotechnology). Following incubation at $4^{\circ} \mathrm{C}$ for $10 \mathrm{~min}$, the total lysates were centrifuged at $1,400 \mathrm{xg}$ for $15 \mathrm{~min}$ at $4^{\circ} \mathrm{C}$, and then the super- 

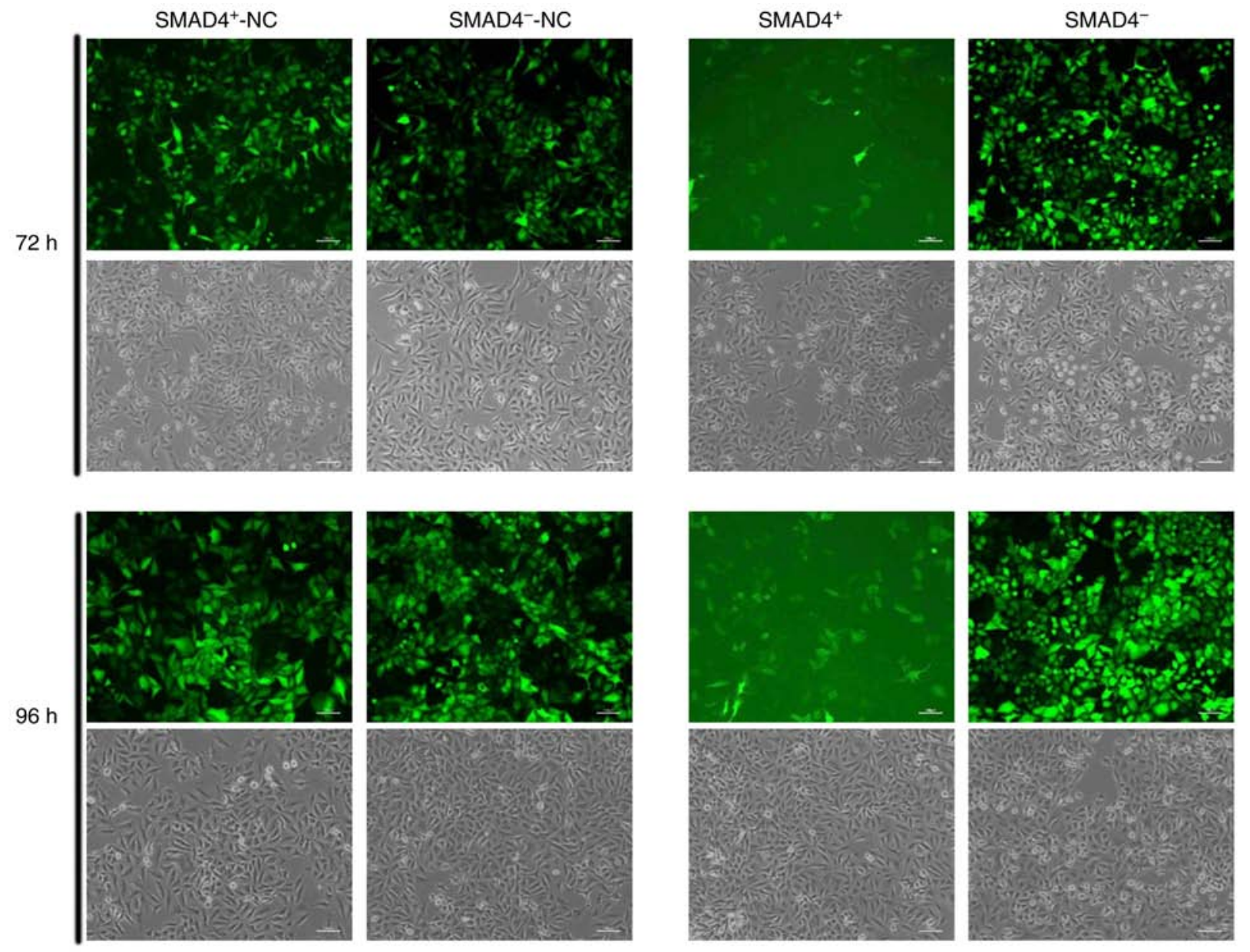

Figure 1. Representative picture of four types of lentivirus (LV-SMAD4+, LV-SMAD4+-NC, LV-SMAD4- and LV-SMAD4-NC) that infected A549 cell lines subsequent to 72 and $96 \mathrm{~h}$, examined under optical and fluorescence microscopy with a x100 magnification. Four types of lentivirus (LV-SMAD4 ${ }^{+}$, LV-SMAD4+-NC, LV-SMAD4- and LV-SMAD4-NC) were marked with green fluorescent protein, so the green indicates that the specific lentivirus infected A549 cell lines. The length of the scale bars in the figure is $100 \mu \mathrm{m}$. LV, lentivirus; SMAD4, SMAD family member 4; NC, negative control.

natant was extracted. Protein concentration was determined with bicinchoninic acid protein assay kit (cat. no. G2026; Servicebio Inc.), according to the bicinchoninic acid protein quantification method (sourced from Beyotime Institute of Biotechnology). Subsequently, $2 \mu 1$ 5xSDS-PAGE (Beyotime Institute of Biotechnology) loading buffer was added to $8 \mu \mathrm{l}$ supernatant for $10 \mathrm{~min}$ at $100^{\circ} \mathrm{C}$. Approximately $40 \mu \mathrm{g}$ protein per well was separated by $10 \%$ SDS-PAGE electrophoresis (Bio-Rad Laboratories, Inc.), transferred to polyvinylidene fluoride membranes (EMD Millipore), blocked with 5\% skimmed milk powder in tris-buffered saline with $0.05 \%$ Tween-20 (TBST) buffer for $1 \mathrm{~h}$ at room temperature, and then immunoblotted with primary antibodies overnight at $4^{\circ} \mathrm{C}$. Subsequent to washing four times with TBST, the membranes were further incubated with the horseradish peroxidase-conjugated anti-rabbit secondary antibody (1:2,000; cat. no. 7074; Cell Signaling Technology, Inc.) for $2 \mathrm{~h}$ at room temperature. Finally, immunodetection was performed using an Enhanced Chemiluminescence system (cat. no. G2014; Servicebio Inc.) and analyzed using ImageJ software (version 2.1; National Institutes Health), following a further four washes with TBST. All antibodies used for western blotting were as follows: Anti-Smad4 (1:1,000; cat. no. 46535; Cell Signaling Technology, Inc.), anti-BMP4 (1:10,000; cat. no. ab124715;
Abcam, Cambridge, MA, USA), anti-SP-A (1:1,000; cat. no. sc-80621; Santa Cruz Biotechnology, Inc.), anti-SP-B (1:1,000; cat. no. sc-133143; Santa Cruz Biotechnology, Inc.), Anti-proSP-C (1:500; cat. no. 2464523; EMD Millipore) and anti- $\beta$-actin (1:5,000; cat. no. 4967; Cell Signaling Technology, Inc.).

Statistical analysis. All data were presented as the mean \pm standard deviation. The data were analyzed using SPSS 17.0 (SPSS, Inc.) and GraphPad Prism 5.0 (GraphPad Software, Inc.) statistical packages, and evaluated using a Student's t-test between the two groups. $\mathrm{P}<0.05$ was considered to indicate a statistically significant difference.

\section{Results}

Effect of SMAD4 on the expression of SPs and the BMP4/activin/TGF- $\beta$ signaling pathway. The optimal puromycin concentration was determined to be $1.2 \mu \mathrm{g} / \mathrm{ml}$, and the efficiency of lentivirus infection was observed by microscope after 72 and $96 \mathrm{~h}$ (Fig. 1). To confirm the transfection efficiency of LV-SMAD4 ${ }^{+}$and LV-SMAD4- in A549, SMAD4 expression levels were determined by RT-qPCR and western blotting. LV-SMAD4+ ${ }^{+}$transfection significantly 
A
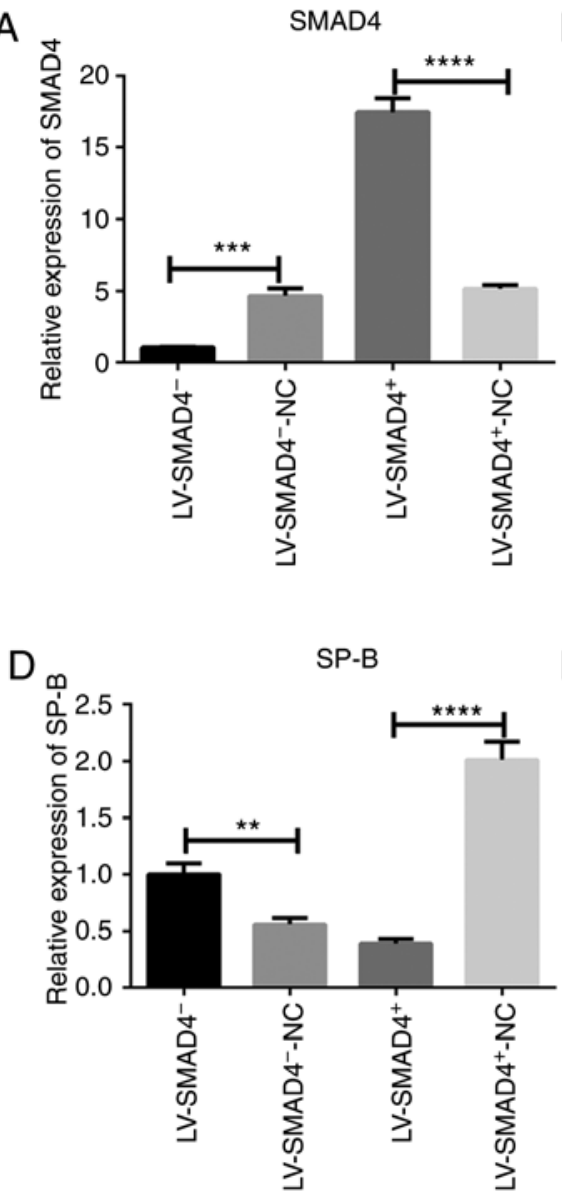

$\mathrm{B}$

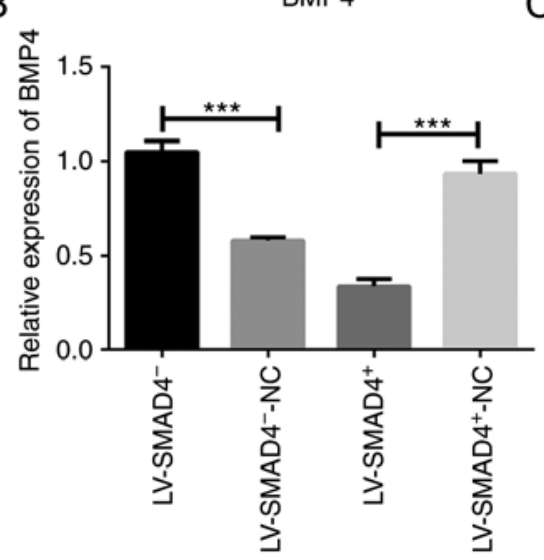

E

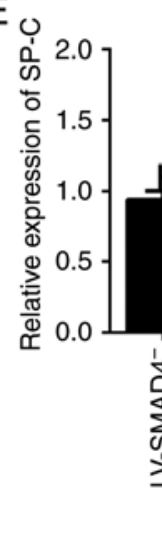

C

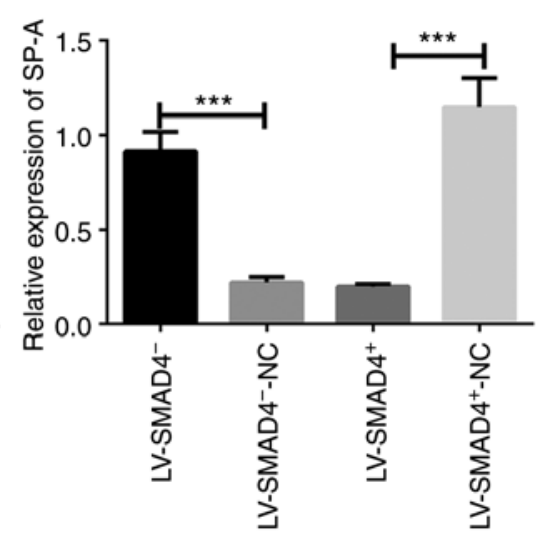

Figure 2. Validation of the expression of SMAD4, BMP4, SPs and miR-431 in four types of stable cell lines with lentivirus (LV-SMAD4 ${ }^{+}, \mathrm{LV}_{-} \mathrm{SMAD} 4^{+}-\mathrm{NC}$, LV-SMAD4- and LV-SMAD4-NC) determined using reverse transcription-quantitative PCR. (A) SMAD4 mRNA expression levels in cell lines with lentivirus. (B) BMP4 mRNA expression levels in cell lines with lentivirus. (C) SP-A mRNA expression levels in cell lines with lentivirus. (D) SP-B mRNA expression levels in cell lines with lentivirus. (E) SP-C mRNA expression levels in cell lines with lentivirus. (F) miR-431 mRNA expression levels in cell lines with lentivirus. ${ }^{* *} \mathrm{P}<0.001,{ }^{* * * *} \mathrm{P}<0.0005$ and ${ }^{* * * *} \mathrm{P}<0.0001$ with comparisons shown by lines. LV, lentivirus; SMAD4, SMAD family member 4 ; NC, negative control; BMP4, bone morphogenetic protein 4; SP, surfactant proteins; miR, microRNA.

increased the expression levels of SMAD4 in cells compared with LV-SMAD4 ${ }^{+}-\mathrm{NC}(\mathrm{P}<0.0005)$, and LV-SMAD4significantly decreased the expression of SMAD4 compared with LV-SMAD4-NC ( $\mathrm{P}<0.05$; Figs. $2 \mathrm{~A}$ and $3 \mathrm{~A}$ and $\mathrm{B})$. Furthermore, to investigate whether SMAD4 serves a function in SP expression via the BMP4/activin/TGF- $\beta$ signaling pathway, the expression levels of SPs (SP-A, SP-B and SP-C) and BMP4 were determined by RT-qPCR. It was revealed that SP-A, SP-B, SP-C and BMP4 exhibited increased expression levels in LV-SMAD4- cells compared with LV-SMAD4-NC $(\mathrm{P}<0.001)$. On the contrary, the expression levels of the SPs and BMP4 were significantly decreased in $\mathrm{LV}_{-\mathrm{SMAD}}{ }^{+}$cells compared with LV-SMAD4+ ${ }^{+} \mathrm{NC}$ cells $(\mathrm{P}<0.0005$; Fig. 2$)$. To confirm this effect at the protein level, cell lines with stable lentivirus transfection were harvested for western blotting. Similar results were observed via western blotting, although the differences were not as significant as those observed by RT-qPCR (Fig. 3). In addition, miR-431 expression levels were also significantly increased when SMAD4 was overexpressed compared with LV-SMAD4+-NC cells ( $\mathrm{P}<0.0001$; Fig. 2).

miR-431 inhibits the expression of SPs by inhibiting the BMP4/activin/TGF- $\beta$ signaling pathway. A previous study demonstrated that miR-431 may negatively regulate lung development by targeting SMAD4 (13). In the present study, the mechanism of the miR-431-mediated inhibition of the expression of SPs via BMP4/activin/TGF- $\beta$ signaling in A549 cells treated with SMAD4 was investigated. A549 cells were treated with miR-431 mimic in combination with LV-SMAD4-, which resulted in the significantly increased expression levels of BMP4 $(\mathrm{P}<0.0001)$ and significantly reduced expression levels of the SPs $(\mathrm{P}<0.05)$ at the mRNA level compared with cells transfected with miR-431 mimic-NC. On the contrary, cells treated with the miR-431 inhibitor in combination with LV-SMAD4- exhibited significantly reduced expression levels of BMP4 $(\mathrm{P}<0.001)$ and significantly increased expression levels of SPs $(\mathrm{P}<0.05)$ at the mRNA level compared with cells transfected with miR-431 inhibitor-NC (Fig. 4). The changes in protein expression levels of the SPs were consistent with the changes at mRNA level, while the relative expression levels of BMP4 at the protein level was different to that observed at the mRNA level (Fig. 5). Overexpression of miR-431 combined with LV-SMAD4 ${ }^{+}$resulted in the significantly reduced expression levels of SPs $(\mathrm{P}<0.05)$, and the expression levels of BMP4 were significantly increased at the mRNA and protein levels $(\mathrm{P}<0.05)$ compared with the negative control. Cells with the 
A

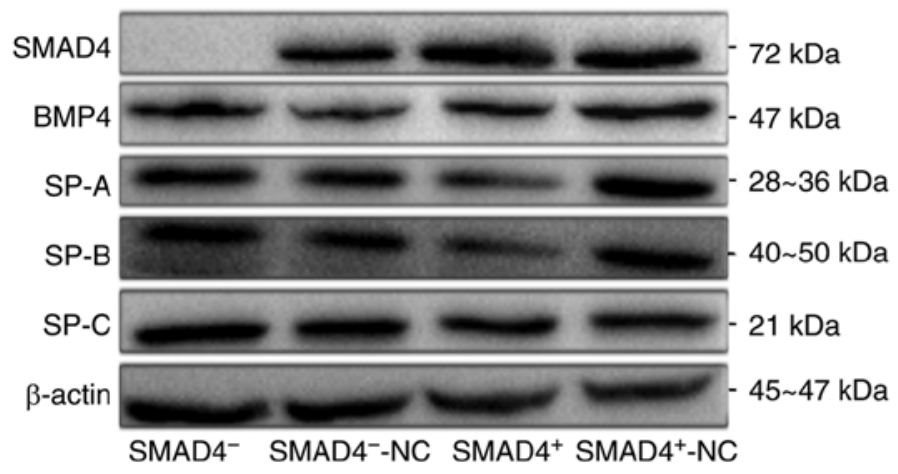

C

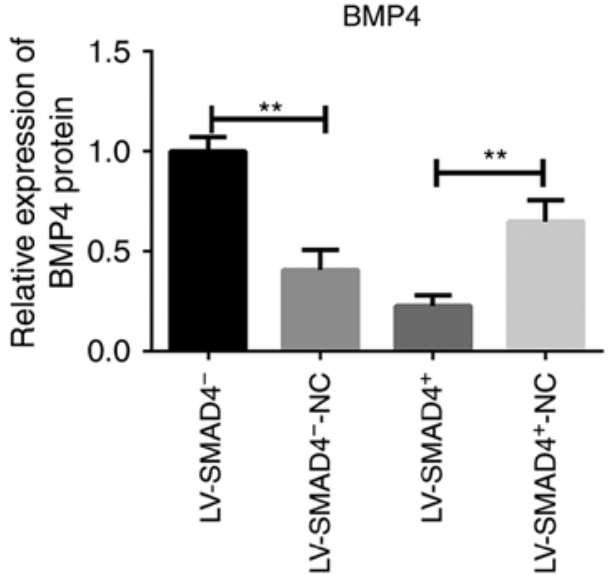

E

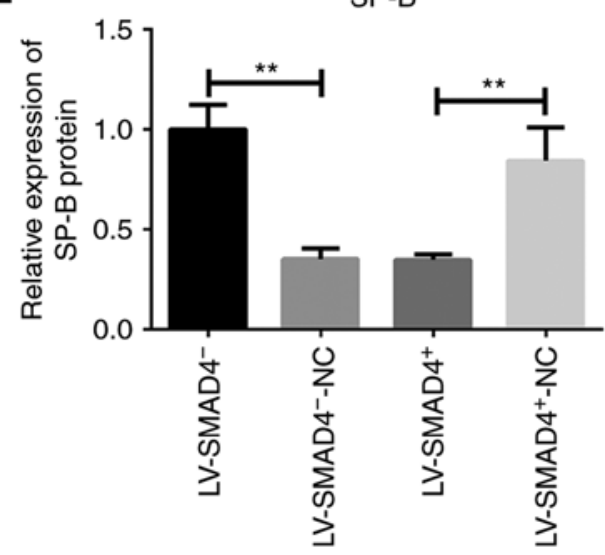

B

SMAD4

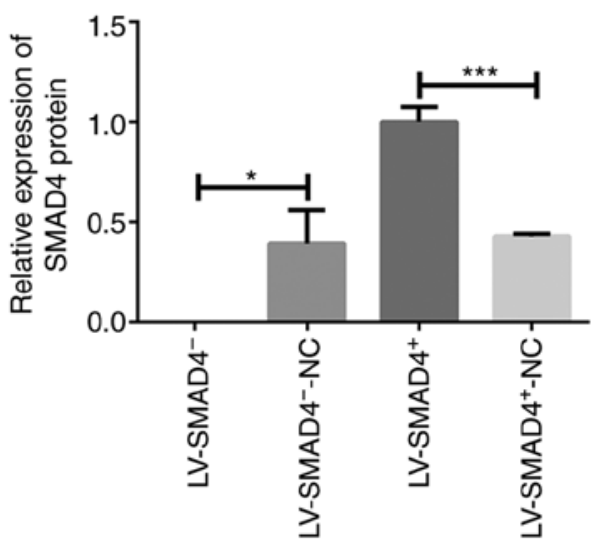

D

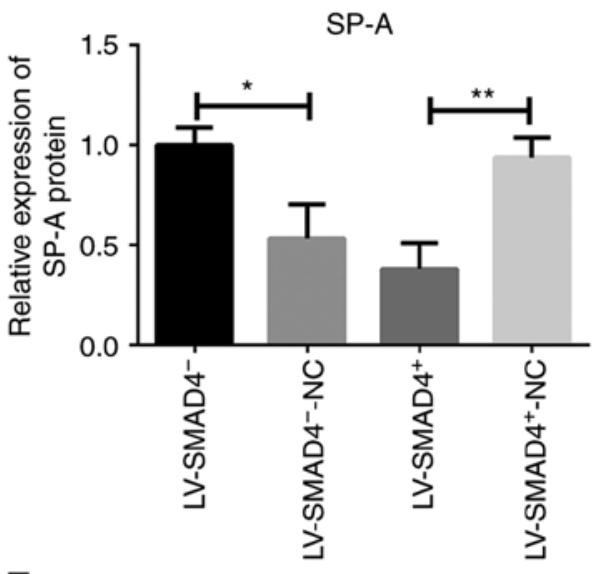

$\mathrm{F}$

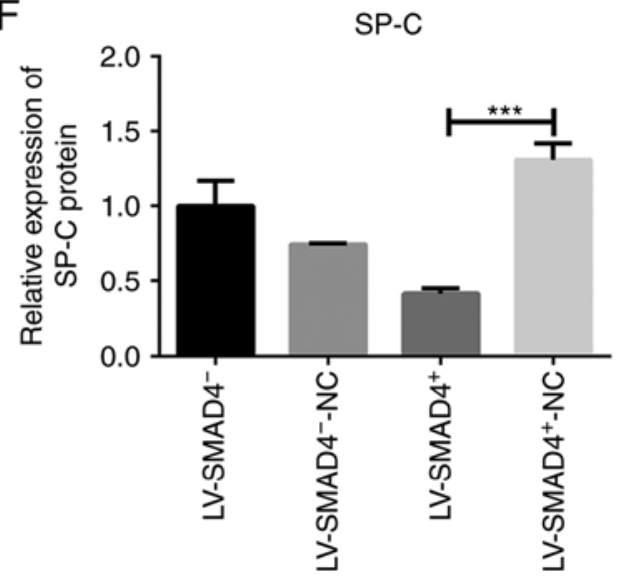

Figure 3. Western blotting was used to detect the protein expression levels of SMAD4, BMP4 and SPs in four types stable cell lines with lentivirus (LV-SMAD4 ${ }^{+}$, LV-SMAD4 ${ }^{+}-N C$, LV-SMAD4- and LV-SMAD4-NC). (A) Western blotting results for SMAD4, BMP4 and SPs (SP-A, SP-B and SP-C), with $\beta$-actin used as an internal control. (B) Relative expression levels of SMAD4 protein. The data confirmed the transfection efficiency of four types of stable cell lines with lentivirus (LV-SMAD4 ${ }^{+}$, LV-SMAD4 $^{+}-\mathrm{NC}$, LV-SMAD4 ${ }^{-}$and LV-SMAD4-NC). (C) Relative expression levels of BMP4 protein. (D) Relative expression levels of SP-A protein. (E) Relative expression levels of SP-B protein. (F) Relative expression levels of SP-C protein. ${ }^{*} \mathrm{P}<0.05,{ }^{* *} \mathrm{P}<0.001$ and ${ }^{* * * *} \mathrm{P}<0.0005$ with comparisons shown by lines. LV, lentivirus; SMAD4, SMAD family member 4; NC, negative control; BMP4, bone morphogenetic protein 4; SP, surfactant proteins.

inhibition of miR-431 combined with LV-SMAD4 ${ }^{+}$exhibited significantly increased expression levels of SPs $(\mathrm{P}<0.05)$ and reduced expression levels of BMP4 $(\mathrm{P}<0.05)$ at the mRNA and protein levels compared with the inhibitor-NC group. In addition, the expression of SMAD4 was determined subsequent to transfecting miR-431 into LV-SMAD4+ cells, and it was revealed that miR-431 significantly downregulated the expression of SMAD4 compared with the mimic-NC group $(\mathrm{P}<0.001$; Figs. 6 and 7$)$.

\section{Discussion}

Lung development is divided into five stages, the embryonic, pseudoglandular, canalicular, saccular and alveolar stages, and it extends from the embryonic period through the fetal period up to birth and subsequent development (20). Based on the morphological maturity, and the synthesis and secretion of SPs, the main function of the lung is effective gas and blood exchange $(7,20)$. Evidence has demonstrated that a number of 
A

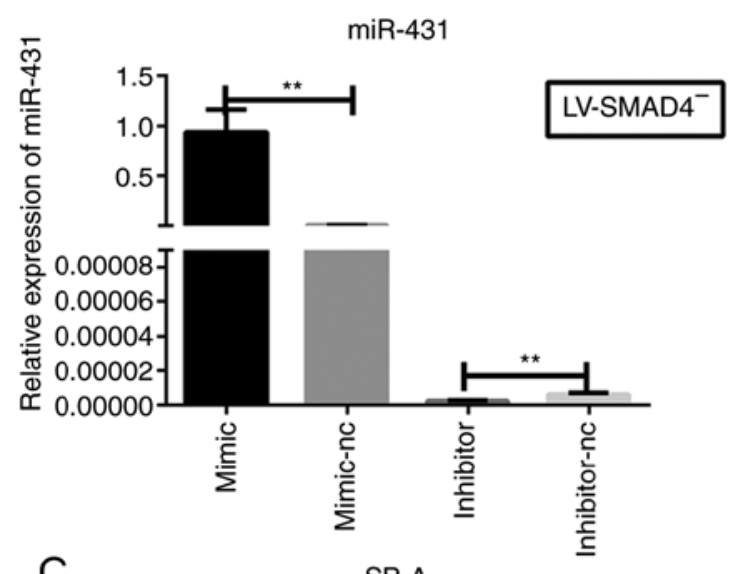

C

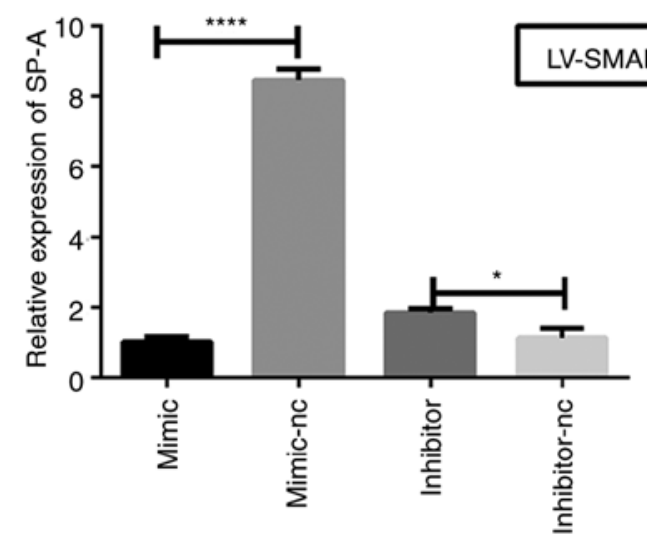

E

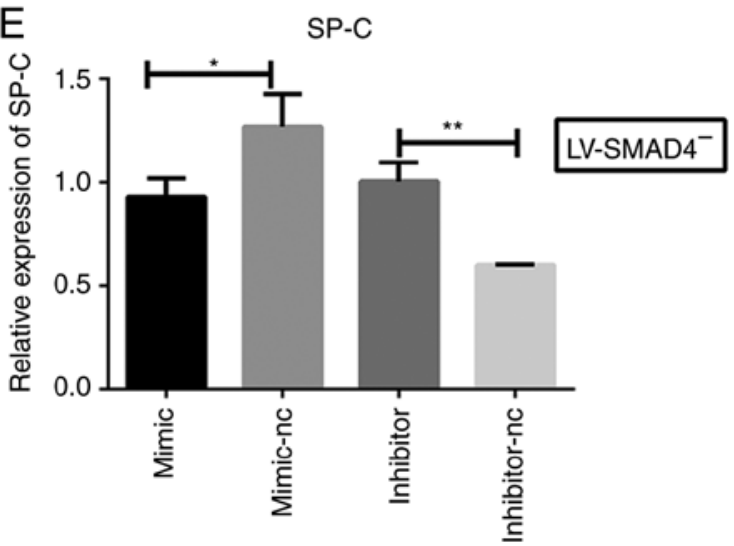

B

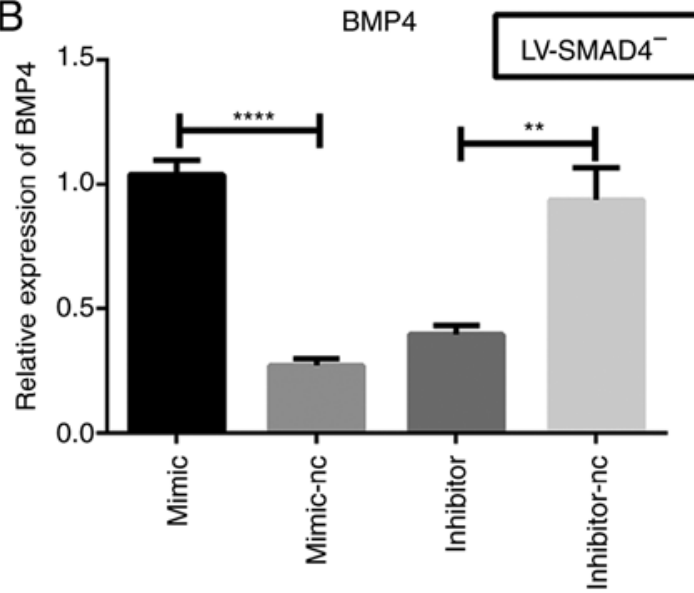

D

SP-B

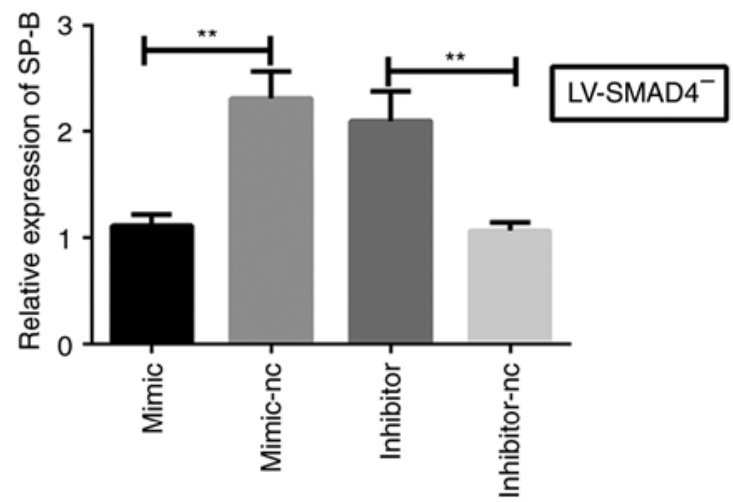

F

SMAD4

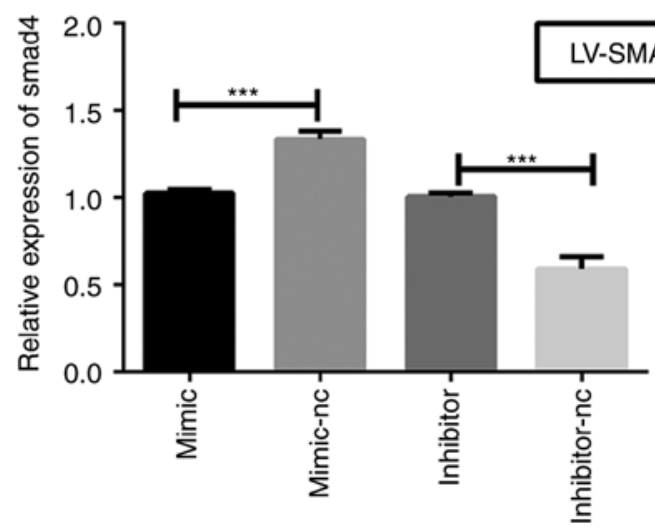

Figure 4. Relative expression levels of miR-431, BMP4, SPs and SMAD4 in stable cell lines with LV-SMAD4 transfected with miR-431 mimic, inhibitor and the corresponding control (mimic-NC and inhibitor-NC) by reverse transcription-quantitative PCR. (A) miR-431 mRNA expression levels were determined in LV-SMAD4- cells to confirm the transfection efficiency of the mimic, inhibitor and the corresponding controls. (B) BMP4 mRNA expression levels in LV-SMAD4 cells transfected with miR-431 mimic, inhibitor and the corresponding control. (C) SP-A mRNA expression levels. (D) SP-B mRNA expression levels. (E) SP-C mRNA expression levels. (F) SMAD4 mRNA expression levels. ${ }^{*} \mathrm{P}<0.05,{ }^{* * *} \mathrm{P}<0.001,{ }^{, * * *} \mathrm{P}<0.0005$ and ${ }^{* * * * *} \mathrm{P}<0.0001$ with comparisons shown by lines. miR, microRNA; LV, lentivirus; SMAD4, SMAD family member 4; NC, negative control; BMP4, bone morphogenetic protein 4; SP, surfactant proteins .

miRNAs (21), including miR-302/367 (22) and the miR-17-92 cluster (23), and multiple signaling pathways, including Hippo $(24,25)$, WNT $(26,27)$ and vascular endothelial growth factor $(28,29)$, participate in the regulation of lung specification and maturation (7). In previous studies, the levels of miR-431 were demonstrated to decline during rat lung development and demonstrated a higher expression in preterm infants with RDS compared with those without RDS $(8,9,14,30)$. SMAD4 was identified as a target gene of miR-431 via TargetScan and luciferase reporter assays, and SPs were differentially expressed in A549 cells overexpressing miR-431 or with miR-431 knocked down (13). In the present study, SMAD4 was revealed to negatively regulate the expression of BMP4 and SPs in A549 cells when overexpressed. As a member of the SMAD family, SMAD4 is mainly expressed in the epithelial cytoplasm, and is associated with other SMADs to negatively regulate lung morphogenesis (31). In addition, a previous study demonstrated that newborn mice with long-term exposure to hyperoxia exhibited the upregulation of SMAD4 and dampening of the BMP4 signaling pathway, which resulted in 

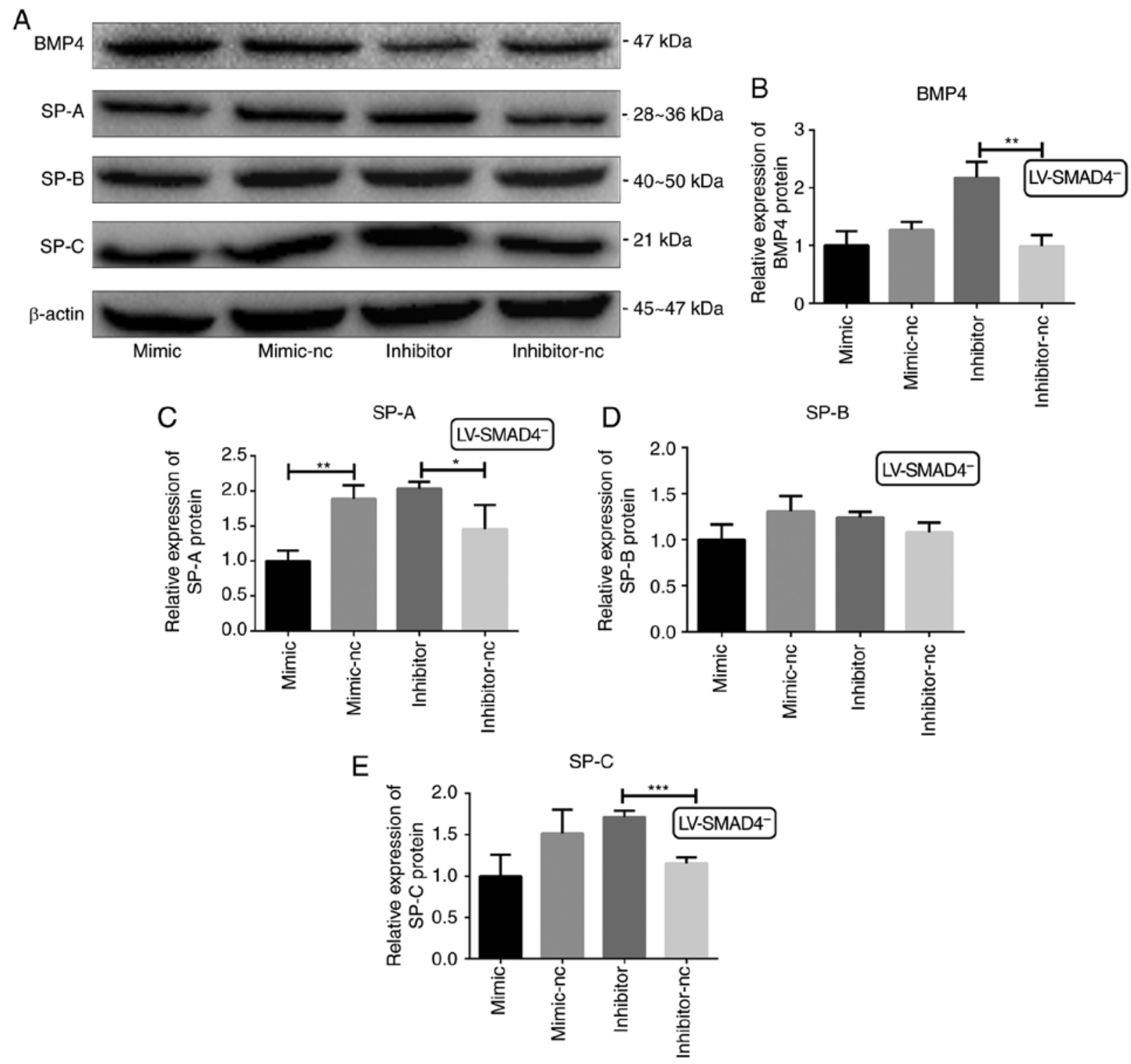

Figure 5. Validation of the expression of BMP4 and SPs (SP-A, SP-B and SP-C) protein levels in stable cell lines with LV-SMAD4- transfected with an miR-431 mimic, inhibitor and the corresponding control (mimic-NC and inhibitor-NC) via western blotting. (A) Western blotting results for BMP4 and SPs (SP-A, SP-B and SP-C), with $\beta$-actin used as the internal control. (B) Relative expression levels of BMP4 protein. (C) Relative expression levels of SP-A protein. (D) Relative expression levels of SP-B protein. (E) Relative expression levels of SP-C protein. ${ }^{*} \mathrm{P}<0.05,{ }^{* * *} \mathrm{P}<0.001$ and ${ }^{* * * *} \mathrm{P}<0.0005$ with comparisons shown by lines. LV, lentivirus; SMAD4, SMAD family member 4; NC, negative control; BMP4, bone morphogenetic protein 4; SP, surfactant proteins.

AECII functional defects, obstruction of normal alveolarization and formation of bronchopulmonary dysplasia (32). The results of the present study are consistent with those reports. In addition, in the present study, the expression level of miR-431 was lower in the SMAD4 knockdown group, indicating that miR-431 negatively regulates the expression of SPs.

The molecular mechanism of miR-431-mediated regulation of the expression of SPs was investigated in the present study by overexpressing or knocking down miR-431, combined with the overexpression or knockdown of SMAD4. The expression of SPs was reduced in the SMAD4 knockdown group via overexpressing miR-431, and increased in the SMAD4 overexpression group via inhibiting miR-431. However, the expression of BMP4 was inconsistent at the protein and mRNA levels in the LV-SMAD4 stable cell line with overexpression or knockdown of miR-431. This inconsistency may be due to the following reasons: i) Transcription of mRNA and protein levels are not necessarily parallel; ii) occasionally, the rate and degree of degradation of mRNA may have impacted the results; iii) post-translational modification of the protein may impact the rate of degradation. Meanwhile, this inconsistency may result in the differences in the expression of SPs at the protein level being not as significant as those observed by RT-qPCR in the LV-SMAD4- stable cell line with overexpression or knockdown of miR-431. Overall, the results indicated that miR-431 negatively regulates the expression of SPs through the inhibition of the BMP4/activin/TGF- $\beta$ signaling pathway.

BMPs are multifunctional growth factors belonging to the TGF- $\beta$ superfamily, and they function through serine/threonine receptor kinases, composed of type I and II subtypes $(33,34)$. The type I receptor kinases may be transphosphorylated by the type II receptor kinases in the TGF- $\beta$ system, and interact with SMADs, including SMAD1, SMAD5, SMAD8 and SMAD4, 
A

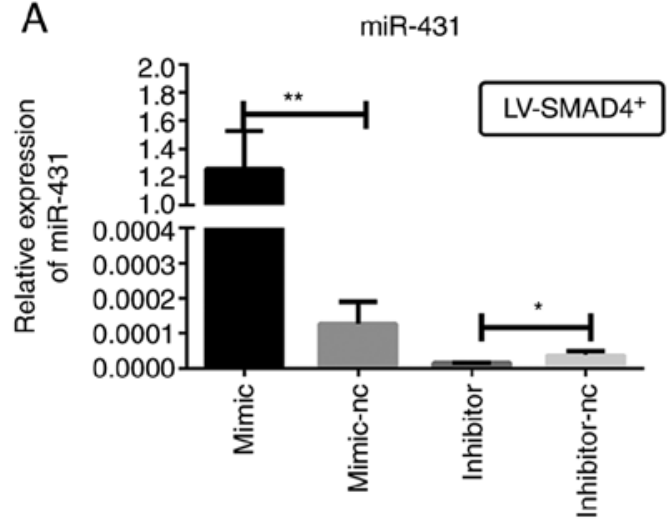

C

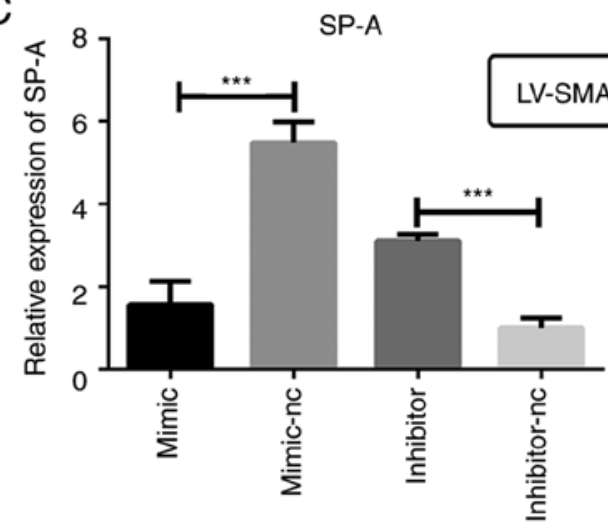

E

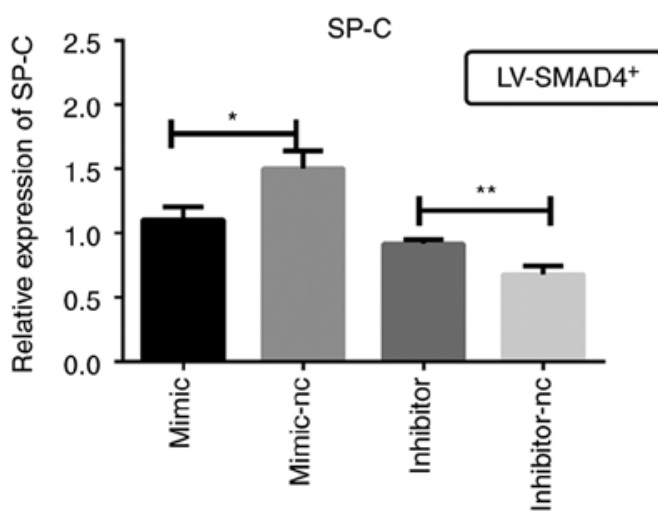

B

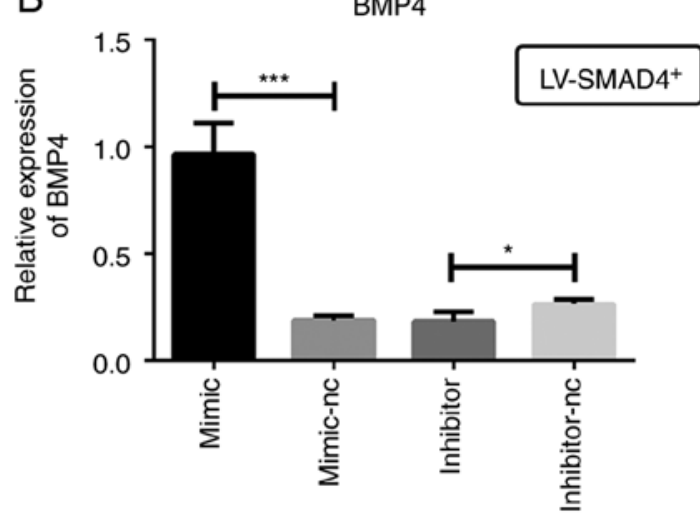

D SP-B

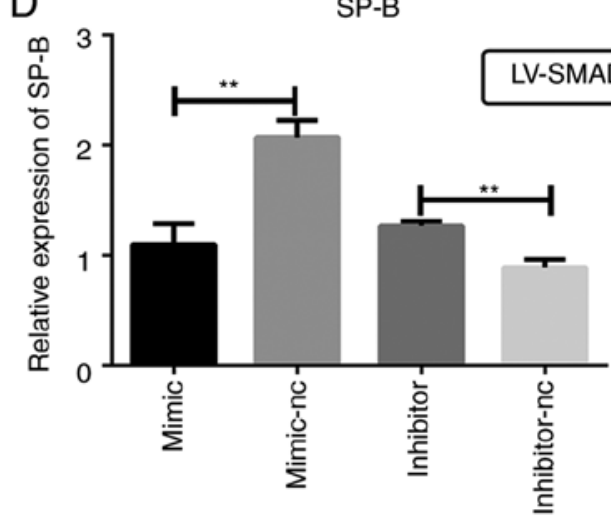

F

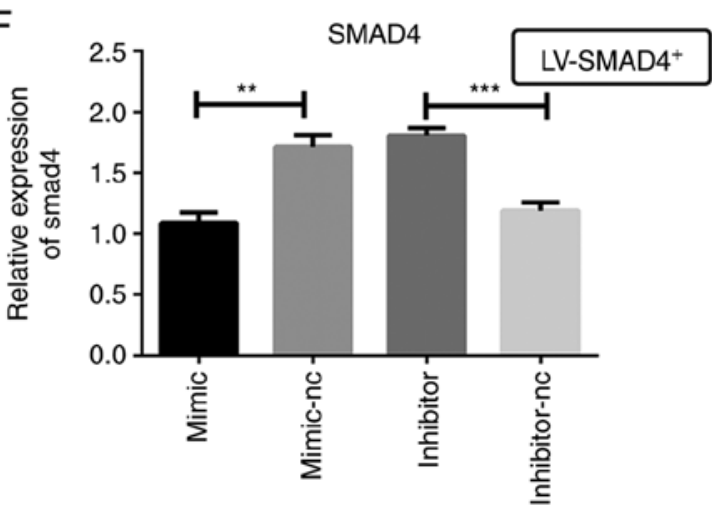

Figure 6. Relative expression of miR-431, BMP4, SPs and SMAD4 in stable cell lines with LV-SMAD4+ transfected with miR-431 mimic, inhibitor and the corresponding control (mimic-NC and inhibitor-NC) determined using reverse transcription-quantitative PCR. (A) miR-431 mRNA expression levels in LV-SMAD4 ${ }^{+}$cells were determined to confirm the transfection efficiency of mimic, inhibitor and the corresponding controls. (B) BMP4 mRNA expression levels. (C) SP-A mRNA expression levels. (D) SP-B mRNA expression levels. (E) SP-C mRNA expression levels. (F) SMAD4 mRNA expression levels. ${ }^{*} \mathrm{P}<0.05,{ }^{* *} \mathrm{P}<0.001$ and ${ }^{* * *} \mathrm{P}<0.0005$ with comparisons shown by lines. LV, lentivirus; SMAD4, SMAD family member 4; NC, negative control; BMP4, bone morphogenetic protein 4; SP, surfactant proteins; miR, microRNA.

to translocate to the nucleus and participate in the regulation of transcription together with other transcription factors (33). The BMP4/activin/TGF- $\beta$ signaling pathway functions in lung development, from mesodermal differentiation to the saccular and alveolarization stages of late lung development $(33,34)$. One study has demonstrated that homozygous BMP4 mutant embryos die between embryonic stage 6.5 and 9.5, and have little or no mesodermal differentiation (35). Addition of BMP4 to the medium surrounding lungs grown in organ culture stimulates cell proliferation and branching morphogenesis (36). Additionally, BMP4/activin/TGF- $\beta$ signaling is active during late lung development, indicating that the BMP4/activin/TGF- $\beta$ signaling pathway serves a notable function in septal and vascular development, and maintains homeostasis of the epithelial layer of the large conducting airways in the mature lung (34). The present results suggest that the BMP4/activin/TGF- $\beta$ signaling pathway also regulates the expression of SPs. miR-431 may inhibit the BMP4/activin/TGF- $\beta$ signaling pathway by targeting SMAD4.

Pulmonary surfactant (PS) is stored in the lamellar bodies of AECII cells (37). PS is a complex of lipids, proteins and carbohydrates, containing at least 4 types of proteins, including SP-A, SP-B, SP-C and SP-D. SP-C is the predominant PS-associated protein, followed by SP-B, SP-A and SP-D in terms of concentration, SP-D is the only type that does not have lipid-containing structures, while the other 3 types (SP-A, 
A

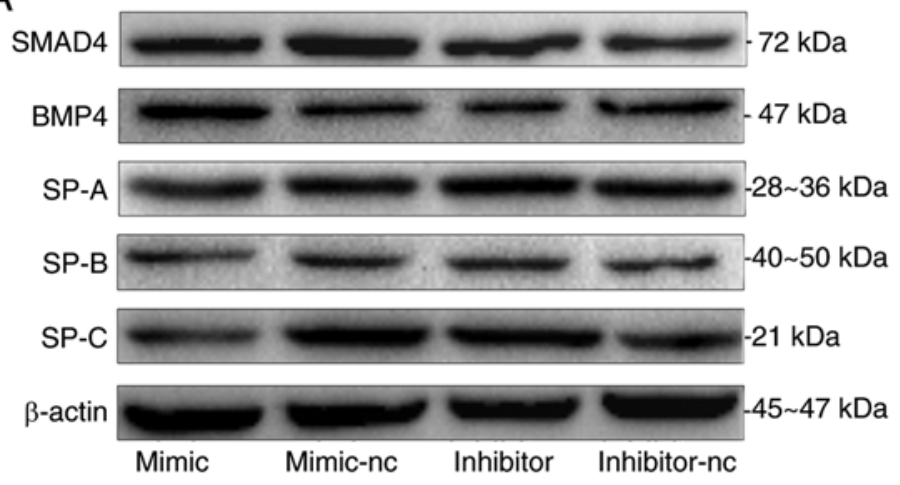

C

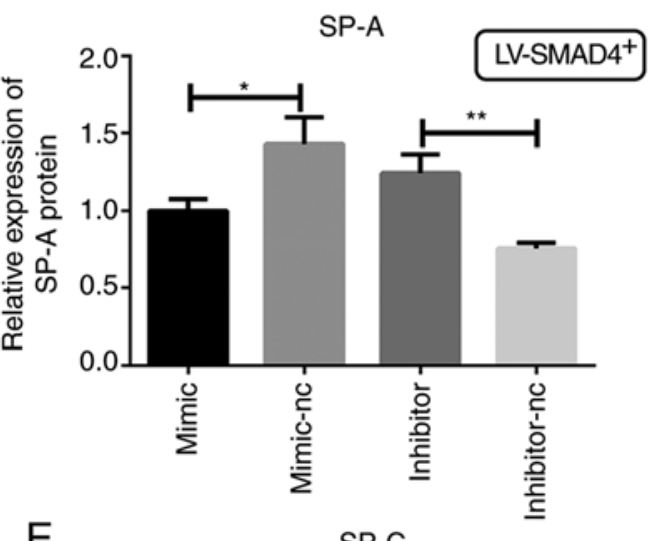

E

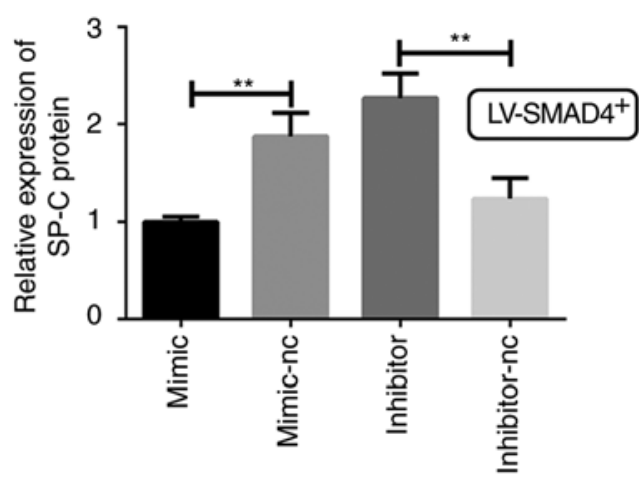

B

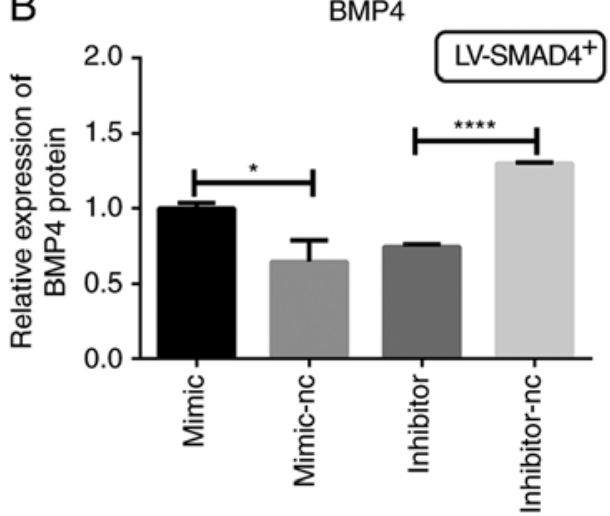

D
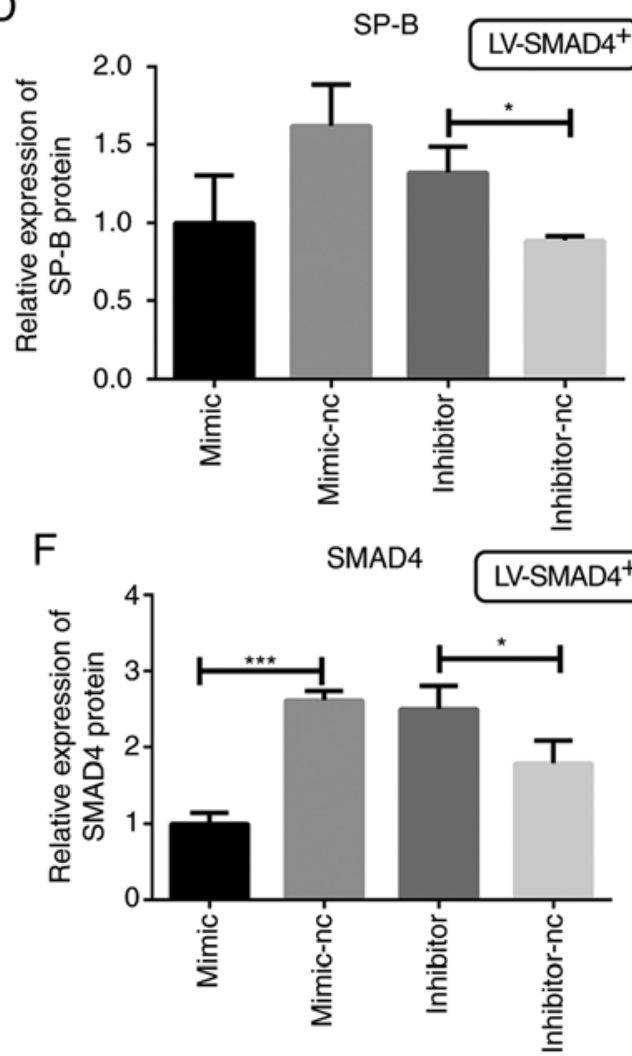

Figure 7. Determination of BMP4, SMAD4 and SPs protein levels in stable cell lines with LV-SMAD4+ transfected with miR-431 mimic, inhibitor and the corresponding control (mimic-NC and inhibitor-NC) though western blotting. (A) Western blotting results for SMAD4, BMP4 and SPs (SP-A, SP-B and SP-C) expression, with $\beta$-actin used as the internal control. (B) Relative expression levels of BMP4 protein. (C) Relative expression levels of SP-A protein. (D) Relative expression levels of SP-B protein. (E) Relative expression levels of SP-C protein. (F) Relative expression levels of SMAD4 protein. "P<0.05, ${ }^{* *} \mathrm{P}<0.001,{ }^{* * *} \mathrm{P}<0.0005$ and ${ }^{* * * * *} \mathrm{P}<0.0001$ with comparisons shown by lines. LV, lentivirus; SMAD4, SMAD family member 4; NC, negative control; BMP4, bone morphogenetic protein 4 ; SP, surfactant proteins.

SP-B and SP-C) have lipid-containing structures $(38,39)$. The quantity of PS is one of the most important indicators of the grade of pulmonary maturity and is closely associated with fetal development (40). The majority of preterm births occur during the late canalicular or saccular stage (weeks 26-36), when distal epithelial progenitors start to give rise to bipotential alveolar epithelial progenitors, and AECII cells are just starting to produce PS (2). PS reduces the surface tension within the alveoli and enhance alveolar expansion, allowing for gas exchange. PS deficiency increases the incidence of alveolar atelectasis, which further reduces the carbon dioxide and oxygen exchange between the pulmonary capillaries and alveoli and ventilation perfusion ratio (V/Q) mismatching ensues $(41,42)$. PS deficiency exacerbates hypoxemia, hyper- carbia and acidosis (41). This is a key mechanism through which PS deficiency causes RDS in preterm infants, resulting in tachypnea, retractions of alveoli, nasal flaring, diminished breath sounds, inspiratory crackles, cyanosis and pallor (42). RDS remains a common disease in preterm infants, although prenatal steroids, respiratory support and PS replacement for neonates have reduced the occurrence (1). Thus, a complete understanding of the molecular mechanisms of lung development, particularly in the synthesis and secretion of PS, is critical for improving clinical practice.

In conclusion, the present study revealed that miR-431 negatively regulates the expression of SPs via inhibition of the BMP4/activin/TGF- $\beta$ signaling pathway by targeting SMAD4 in A549 cells in vitro. These results indicate that the suppression 
of miR-431 may promote the expression of SPs. However, the present study was performed in vitro with only one cell line and does not clarify the connection with other signaling pathways in lung developmental. Therefore, in vivo studies are required to verify whether miR-431 is able to regulate the expression of SPs via inhibition of the BMP4/activin/TGF- $\beta$ signaling pathway by targeting SMAD4. Thus, the specific inhibitors and agonists of key signaling molecules will be used to further investigate the mechanisms of miR-431-mediated lung development in vitro. A tissue-specific miR-431 knockout mouse model will be built using the CRISPR/Cas9 system to further investigate how miR-431 influences in vivo lung development, morphology and function. Moving forward, the challenge will be to further delineate the mechanisms of miR-431, and to develop therapeutic strategies to selectively inhibit miR-431 or SMAD4 and enhance the BMP4/activin/TGF- $\beta$ signaling pathway to effectively prevent or treat lung developmental diseases, particularly RDS.

\section{Acknowledgements}

Not applicable.

\section{Funding}

The present study was supported by the National Natural Science Foundation of China (grant no. 81601321) and the Jiangsu Science and Education Talents Program (grant no. QNRC2016092).

\section{Availability of data and materials}

The datasets used and/or analyzed during the current study are available from the corresponding author on reasonable request.

\section{Authors' contributions}

YY, XYZ and XGZ conceived and designed the experiments of the current study. YQS, ZDB and JJP performed the experiments. YQS, ZDB, XNM and RC analyzed the data. YQS, YY and $X Y Z$ drafted the manuscript. ZDB revised the manuscript. All authors read and approved the final manuscript.

\section{Ethics approval and consent to participate}

Not applicable.

\section{Patient consent for publication}

Not applicable.

\section{Competing interests}

The authors declare that they have no competing interests.

\section{References}

1. Condò V, Cipriani S, Colnaghi M, Bellù R, Zanini R, Bulfoni C, Parazzini F and Mosca F: Neonatal respiratory distress syndrome: Are risk factors the same in preterm and term infants? J Matern Fetal Neonatal Med 30: 1267-1272, 2017.
2. Volckaert $\mathrm{T}$ and De Langhe SP: Wnt and FGF mediated epithelial-mesenchymal crosstalk during lung development. Dev Dyn 244: 342-366, 2015.

3. Colin AA, McEvoy C and Castile RG: Respiratory morbidity and lung function in preterm infants of 32 to 36 weeks' gestational age. Pediatrics 126: 115-128, 2010.

4. Mahoney AD and Jain L: Respiratory disorders in moderately preterm, late preterm, and early term infants. Clin Perinatol 40: 665-678, 2013.

5. Sweet DG, Carnielli V, Greisen G, Hallman M, Ozek E, Plavka R, Saugstad OD, Simeoni U, Speer CP, Vento M, et al: European consensus guidelines on the management of neonatal respiratory distress syndrome in preterm infants-2013 update. Neonatology 103: 353-368, 2013.

6. Ameis D, Khoshgoo N, Iwasiow BM, Snarr P and Keijzer R: MicroRNAs in lung development and disease. Paediatr Respir Rev 22: 38-43, 2017.

7. Herriges M and Morrisey EE: Lung development: Orchestrating the generation and regeneration of a complex organ. Development 141: 502-513, 2014.

8. Kan Q, Ding S, Yang Y and Zhou X: Expression profile of plasma microRNAs in premature infants with respiratory distress syndrome. Mol Med Rep 12: 2858-2864, 2015.

9. Sun ZY, Shen YQ, Chen XQ, Zhou XY, Cheng R, Bao ZD and Yang Y: Expression and potential regulation of miRNA-431 during lung development of Sprague-Dawley rats. Mol Med Rep 19: 4980-4988, 2019.

10. Wu J, Wang Y, Liu G, Jia Y, Yang J, Shi J, Dong J, Wei J and Liu X: Characterization of air-liquid interface culture of A549 alveolar epithelial cells. Braz J Med Biol Res 51: e6950, 2017.

11. Grek CL, Newton DA, Qiu Y, Wen X, Spyropoulos DD and Baatz JE: Characterization of alveolar epithelial cells cultured in semipermeable hollow fibers. Exp Lung Res 35: 155-174, 2009.

12. Ryndak MB, Singh KK, Peng Z and Laal S: Transcriptional profile of Mycobacterium tuberculosis replicating in type II alveolar epithelial cells. PLoS One 10: e0123745, 2015.

13. Li S, Sun Z, Chen T, Pan J, Shen Y, Chen X, Zhou X, Cheng R and Yang Y: The role of miR-431-5p in regulating pulmonary surfactant expression in vitro. Cell Mol Biol Lett 24: 25, 2019.

14. Shen YQ, Yang Y, Sun ZY, Li SJ, Shen JX and Zhou XY: Continuous expression of miR-431 during lung development in Sprague-Dawley rats. Zhongguo Dang Dai Er Ke Za Zhi 21: 287-293, 2019 (In Chinese).

15. Shi Y and Massagué J: Mechanisms of TGF-beta signaling from cell membrane to the nucleus. Cell 113: 685-700, 2003.

16. Zeng Y, Zhu J, Shen D, Qin H, Lei Z, Li W, Huang JA and Liu Z: Repression of Smad4 by miR-205 moderates TGF- $\beta$-induced epithelial-mesenchymal transition in A549 cell lines. Int J Oncol 49: 700-708, 2016.

17. Xing Y, Li C, Hu L, Tiozzo C, Li M, Chai Y, Bellusci S, Anderson S and Minoo P: Mechanisms of TGFbeta inhibition of LUNG endodermal morphogenesis: The role of TbetaRII, Smads, Nkx2.1 and Pten. Dev Biol 320: 340-350, 2008.

18. Geng Y, Dong Y, Yu M, Zhang L, Yan X, Sun J, Qiao L, Geng H, Nakajima M, Furuichi T, et al: Follistatin-like 1 (Fstl1) is a bone morphogenetic protein (BMP) 4 signaling antagonist in controlling mouse lung development. Proc Natl Acad Sci USA 108: 7058-7063, 2011.

19. Livak KJ and Schmittgen TD: Analysis of relative gene expression data using real-time quantitative PCR and the 2(-Delta Delta C(T)) method. Methods 25: 402-408, 2001.

20. Mullassery D and Smith NP: Lung development. Semin Pediatr Surg 24: 152-155, 2015.

21. Johar D, Siragam V, Mahood TH and Keijzer R: New insights into lung development and diseases: The role of microRNAs. Biochem Cell Biol 93: 139-148, 2015.

22. Tian Y, Zhang Y, Hurd L, Hannenhalli S, Liu F, Lu MM and Morrisey EE: Regulation of lung endoderm progenitor cell behavior by miR302/367. Development 138: 1235-1245, 2011.

23. Carraro G, El-Hashash A, Guidolin D, Tiozzo C, Turcatel G, Young BM, De Langhe SP, Bellusci S, Shi W, Parnigotto PP and Warburton D: miR-17 family of microRNAs controls FGF10-mediated embryonic lung epithelial branching morphogenesis through MAPK14 and STAT3 regulation of E-Cadherin distribution. Dev Biol 333: 238-250, 2009.

24. Lin C, Yao E and Chuang PT: A conserved MST1/2-YAP axis mediates Hippo signaling during lung growth. Dev Biol 403: $101-113,2015$.

25. Mahoney JE, Mori M, Szymaniak AD, Varelas X and Cardoso WV: The hippo pathway effector Yap controls patterning and differentiation of airway epithelial progenitors. Dev Cell 30: 137-150, 2014. 
26. Zhang M, Shi J, Huang Y and Lai L: Expression of canonical WNT/ $\beta$-CATENIN signaling components in the developing human lung. BMC Dev Biol 12: 21, 2012.

27. Li C, Xiao J, Hormi K, Borok Z and Minoo P: Wnt5a participates in distal lung morphogenesis. Dev Biol 248: 68-81, 2002.

28. Woik N and Kroll J: Regulation of lung development and regeneration by the vascular system. Cell Mol Life Sci 72: 2709-2718, 2015.

29. Liu X, Lin Y, Tian B, Miao J, Xi C and Liu C: Maternal protein restriction alters VEGF signaling and decreases pulmonary alveolar in fetal rats. Int J Clin Exp Pathol 7: 3101-3111, 2014.

30. Yang Y, Kai G, Pu XD, Qing K, Guo XR and Zhou XY: Expression profile of microRNAs in fetal lung development of Sprague-Dawley rats. Int J Mol Med 29: 393-402, 2012.

31. Zhao J, Lee M, Smith S and Warburton D: Abrogation of Smad3 and Smad 2 or of Smad4 gene expression positively regulates murine embryonic lung branching morphogenesis in culture. Dev Biol 194: 182-195, 1998.

32. Alejandre-Alcázar MA, Kwapiszewska G, Reiss I, Amarie OV, Marsh LM, Sevilla-Pérez J, Wygrecka M, Eul B, Köbrich S, Hesse M, et al: Hyperoxia modulates TGF-beta/BMP signaling in a mouse model of bronchopulmonary dysplasia. Am J Physio Lung Cell Mol Physiol 292: L537-L549, 2007.

33. Chen D, Zhao M, Harris SE and Mi Z: Signal transduction and biological functions of bone morphogenetic proteins. Front Biosci 9: 349-358, 2004.
34. Alejandre-Alcázar MA, Shalamanov PD, Amarie OV, Sevilla-Pérez J, Seeger W, Eickelberg O and Morty RE: Temporal and spatial regulation of bone morphogenetic protein signaling in late lung development. Dev Dyn 236: 2825-2835, 2007.

35. Winnier G, Blessing M, Labosky PA and Hogan BL: Bone morphogenetic protein- 4 is required for mesoderm formation and patterning in the mouse. Genes Dev 9: 2105-2116, 1995.

36. Bragg AD, Moses HL and Serra R: Signaling to the epithelium is not sufficient to mediate all of the effects of transforming growth factor beta and bone morphogenetic protein 4 on murine embryonic lung development. Mech Dev 109: 13-26, 2001.

37. Sanders RL, Hassett RJ and Vatter AE: Isolation of lung lamellar bodies and their conversion to tubular myelin figures in vitro. Anat Rec 198: 485-501, 1980.

38. Crouch E and Wright JR: Surfactant proteins a and d and pulmonary host defense. Annu Rev Physiol 63: 521-554, 2001.

39. Weaver TE and Conkright JJ: Function of surfactant proteins B and C. Annu Rev Physiol 63: 555-578, 2001.

40. Parmigiani S, Solari E and Bevilacqua G: Current concepts on the pulmonary surfactant in infants. J Matern Fetal Neonatal Med 18: 369-380, 2005.

41. Rubarth LB and Quinn J: Respiratory development and respiratory distress syndrome. Neonatal Netw 34: 231-238, 2015.

42. Reuter S, Moser C and Baack M: Respiratory distress in the newborn. Pediatr Rev 35: 417-429, 2014. 